Alummoottil N. Jyothi $^{\text {a }}$
Korappatti Sasikiran $^{\text {a }}$
Moothandasseri S. Sajeev $^{\text {a }}$
R. Revamma
Subramoney N. Moorthy

a Central Tuber Crops Research
Institute,
Sreekariyam,
Thiruvananthapuram,
Kerala, India
b Sree Narayana College,
Chempazhanthy,
Thiruvananthapuram,
Kerala, India

\section{Gelatinisation Properties of Cassava Starch in the Presence of Salts, Acids and Oxidising Agents}

\begin{abstract}
The effect of various cations, anions, acids and oxidising agents on the gelatinisation properties of cassava starch was studied and wide variation was observed in the pasting and swelling properties. Sodium chloride and sodium thiosulphate slightly lowered the peak viscosity of cassava starch with increase in concentration, whereas with sodium sulphite, calcium chloride and sodium hypochlorite, a more significant decrease in the viscosity and breakdown was observed. Ferrous sulphate, alum, aluminium chloride and acids enhanced the peak viscosity at lower concentrations followed by a decrease at $1 \%$ and above. Sodium metabisulphite elevated the viscosity at 0.05 and $0.1 \%$, while sodium hypochlorite lowered the viscosity and breakdown. DSC studies showed that aluminium chloride, sodium sulphite, and sodium thiosulphate brought about an increase in $T_{\text {onset }}, T_{\text {end }}$ and $\Delta H$ values at higher concentrations. A decrease in swelling volume was observed from 0.05 to $1 \%$ concentration of sodium chloride and above that there was a gradual increase. With sodium sulphite, a significant increase in swelling volume was observed at 2.5 and $5 \%$ levels. With 0.05 and $0.1 \%$ aluminium chloride and sodium metabisulphite an increase in swelling volume was noticed, but at higher concentrations there was a drastic fall. Sodium chloride, sodium sulphite, sodium thiosulphate and calcium chloride brought about decrease in starch paste clarity with increase in salt concentration, whereas ferrous sulphate, aluminium chloride, sodium hypochlorite, hydrochloric acid and acetic acid improved the starch paste clarity.
\end{abstract}

Keywords: Cassava starch; Salts, influence on properties; Acids, influence on properties; Oxidising agents, influence on properties; Gelatinisation properties

\section{Introduction}

Starch is widely used in paper, textile, adhesive, sweetener and food industries and these applications depend on starch properties such as viscosity, swelling volume, solubility, clarity, etc. Among the different starches used by the industry, cassava starch is very important in view of its easy extractability, high viscosity and paste clarity. Starch is normally used along with other ingredients like salts, surfactants, acids, sugars or fats and these are reported to modify the physicochemical properties of starch. Perchloric acid and surfactants such as glyceryl monostearate, sodium lauryl sulphate and cetyl trimethyl ammonium chloride are known to affect the viscosity, swelling volume and blue value of starch [1]. Monoglycerides were found to reduce the swelling volume and solubility, whereas addition of polar lipids did not affect the swelling of starch [2,3]. Sodium sulphite and sodium

Correspondence: Alummoottil N. Jyothi, Division of Crop Utilization, Central Tuber Crops Research Institute, Sreekariyam, Thiruvananthapuram - 695 017, Kerala, India. E-mail: sreejyothi in@yahoo.com.

(c) 2005 WILEY-VCH Verlag GmbH \& Co. KGaA, Weinheim thiosulphate brought about decrease in swelling volume of cassava starch at very low concentrations $(<0.01 \%)$ of the salts $[4,5]$. Various ionic and non-ionic water-soluble salts were reported to affect the gelatinisation temperature, hot paste stability and cold setting properties of cassava flour [6]. Eliasson observed delay in gelatinisation of starch in presence of various sugars. In the presence of sugar, there are fewer water molecules in the vicinity of the starch molecules (i.e., the plasticising effect of water decreases) and when starch is gelatinised at limited amount of water (i.e., when a double peak is present in DSC endotherm) the double endotherm is transformed into a single peak and there is a decrease in the gelatinisation temperature range [7].

Although the effects of salts on the rheological properties of starch have been well studied, most of these reports are conflicting. Moreover, the literature available on the effect of chemicals on cassava starch and flour is scattered. Therefore, a systematic study was undertaken to investigate the effect of various cations and anions (monovalent, divalent and trivalent), acids and oxidising agents on the thermal and rheological properties of cassava starch. 


\section{Materials and Methods}

All the chemicals used were of analytical grade. Cassava starch was obtained from Sagoserve, Salem, India. The salts used in this study were aluminium chloride, calcium chloride, sodium chloride, ammonium chloride, sodium thiosulphate, sodium sulphite, ferrous sulphate and potassium aluminium sulphate (alum). The oxidising agents and acids used included sodium hypochlorite, sodium metabisulphite, hydrochloric acid and acetic acid (Qualigens, Mumbai, India). The concentration of these chemicals ranged from 0.05 to $5 \%$. The viscosity of the starch was determined in the presence of different salts, using a Rapid Visco Analyser (RVA-4, Newport Scientific, Warriewood, NSW, Australia), at a starch concentration of $10 \%$ (2.5 g in $25 \mathrm{~g}$ salt solution) and a constant speed of $160 \mathrm{rpm}$ using Standard I profile. The temperature profile employed was as follows: heating range -50 to $95^{\circ} \mathrm{C}$ at a rate of $12^{\circ} \mathrm{C} / \mathrm{min}$, holding at $95^{\circ} \mathrm{C}$ for $2 \mathrm{~min}$, cooling to $50^{\circ} \mathrm{C}$ at $12^{\circ} \mathrm{C} / \mathrm{min}$ and holding at $50^{\circ} \mathrm{C}$ for $2 \mathrm{~min}$. The values recorded were peak viscosity (maximum viscosity attained by the starch paste), holding or hot paste viscosity (hold) i.e., minimum viscosity during stirring at $95^{\circ} \mathrm{C}$, breakdown viscosity (peak - hold), final viscosity i.e., viscosity at the end of the cycle at $50{ }^{\circ} \mathrm{C}$, setback viscosity (final - hold) and pasting temperature. DSC was run using a Seiko 6200 Differential Scanning Calorimeter (Seiko, Tokyo, Japan) equipped with built-in software. Of each starch sample 1-3 mg (with an accuracy of $\pm 0.001 \mathrm{mg}$ ) was transferred into a pre-weighed aluminium pan and a weighed quantity of salt solution was added to give a water-starch ratio of 3:1. The pan was sealed hermetically and transferred to the heating pan of the DSC. An empty pan was used as reference and indium as standard. The sample was heated from 10 to $140{ }^{\circ} \mathrm{C}$ at a rate of $5^{\circ} \mathrm{C} / \mathrm{min}$ and cooled back to $20^{\circ} \mathrm{C}$ at the same rate.

Gelatinisation properties, viz., temperature of onset or start of gelatinisation (DSC onset $-T_{\mathrm{o}}$ ), the temperature at peak minimum (DSC peak $-T_{\mathrm{p}}$ ), offset or end temperature (DSC end $-T_{\mathrm{e}}$ ) and gelatinisation enthalpy $(\Delta H)$ were recorded by means of the built-in software. The swelling volume at $90^{\circ} \mathrm{C}$ and paste clarity of the starch was determined according to standard procedures $[8,9]$. The paste clarity was measured as percent light transmittance (\% $T)$ at $700 \mathrm{~nm}$, using a Unicam UV/Visible Spectrophotometer (Cambridge, UK). All the experiments were done in triplicate and the data were analysed using the statistical package of Genstat 6.0 to calculate the standard deviations.

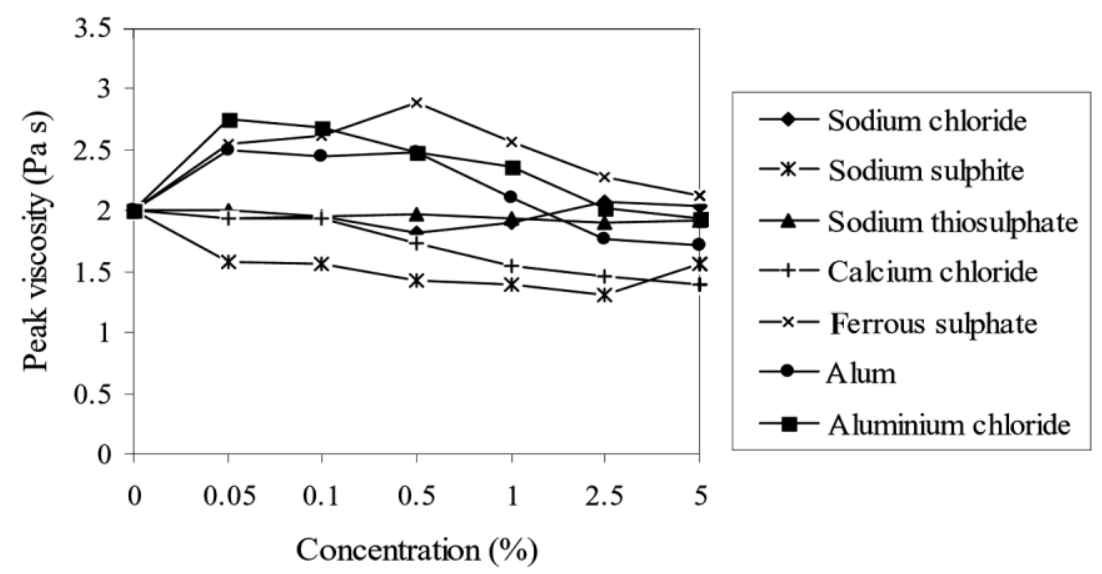

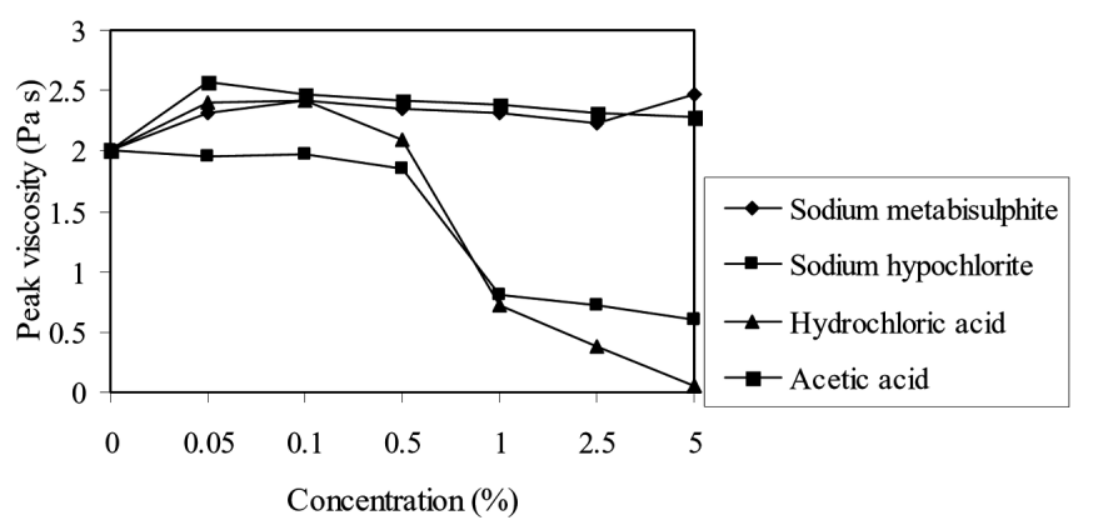

(c) 2005 WILEY-VCH Verlag GmbH \& Co. KGaA, Weinheim
Fig. 1. Effect of different salts, oxidising agents and acids on the peak viscosity (RVA) of cassava starch. 


\section{Results and Discussion}

\subsection{Effect of salts on peak viscosity}

The peak viscosity values of cassava starch in the presence of monovalent, divalent, trivalent and mixed salts, acids and oxidising agents are shown in Fig. 1. The peak viscosity of the starch without the addition of any salt was 2.0 Pa s. No significant change in viscosity was observed when the concentration of sodium chloride was increased from 0.05 to $1.0 \%$; however, a slight increase was noticed at 2.5 and $5.0 \%$ concentrations $(2.08$ and $2.04 \mathrm{~Pa} \mathrm{~s}$ respectively). Bircan and Barringer correlated the increase in peak viscosity of maize starch on addition of sodium chloride to the strong starch-salt interaction, and suggested that this interaction leads to reduced mobility for the gelatinised starch leading to higher viscosity [10]. Sodium-23 NMR studies indicated that when starch is gelatinised, the mobility of $\mathrm{Na}^{+}$ions is decreased because of salt-starch interaction [11]. Unlike potato and maize starches, cassava starch does not contain any lipids, proteins or fibre, where these components also influence the viscosity by interaction with the salts. The absence of a significant effect of sodium chloride on the peak viscosity of cassava starch could be due to the difference in starch composition.

Sodium sulphite, sodium thiosulphate and calcium chloride caused a gradual decrease in viscosity with increase in concentration of the salts, which was more significant with sodium sulphite and higher concentrations of calcium chloride. Sodium sulphite decreased the peak viscosity from $2.01 \mathrm{~Pa} \mathrm{~s}$ at $0.05 \%$ to $1.31 \mathrm{~Pa}$ s at $2.5 \%$, a slight increase to $1.56 \mathrm{~Pa}$ s was seen at $5 \%$ concentration. With $\mathrm{CaCl}_{2}$, there was a drop in viscosity from 1.93 to $1.41 \mathrm{~Pa}$ s, when the concentration increased from 0.05 to $5 \%$. In the case of sodium thiosulphate, the decrease was small, i.e., from 2.01 at $0.05 \%$ to $1.92 \mathrm{~Pa}$ s at the $5 \%$ level. Hill and Gray also reported a decrease in viscosity of cassava starch in the presence of sodium sulphite [12]. This effect could be due to oxidative reductive depolymerisation (ORD) of starch in the presence of sodium sulphite, which brings about both lowering of viscosity and swelling volume [4]. Sulphite reacts stoichiometrically with oxygen in the ratio 2:1 resulting in the removal of oxygen and leading to the formation of sulphite free radicals and superoxide ion $\left(. \mathrm{O}_{2}^{-}\right)$[13]. It is evident that with the level of sulphite in the reaction mixture, which produced the minimum in swelling volume, there will be an excess of sulphite which will ensure the complete removal of molecular oxygen with the accompanying production of superoxide ions and sulphite free radicals. These ions contribute to a large extent to the depolymerisation process [14]. The sulphite free radicals may be acting in two ways, they may have an intrinsic activity of their own or alternatively, they may provide by regeneration within the propagation sequence further supplies of superoxide ions. At higher levels of sulphite, the oxygen is totally scavenged from the system and a free radical termination process begins to dominate the reaction. This explains the recovery in the swelling volume at higher sulphite levels [4].

A similar drop in viscosity was obtained in Brabender studies on the effect of sodium thiosulphate on the viscosity properties of cassava starch [5]. It has been observed that sodium thiosulphate at some definite concentrations, lowered the swelling volumes to very low values, but the Brabender viscosity was not affected at the same concentrations [5]. At higher concentrations and continuous stirring the ORD may not be prominent and hence there was no effect on viscosity $[4,10]$. Moore et al. reported that addition of calcium chloride brings about lowering of viscosity of potato starch. On the other hand, $0.5 \mathrm{M}$ and $1 \mathrm{M}$ calcium chloride slightly increased the peak viscosity of maize starch [15]. Our results are also similar to that observed with potato starch.

Addition of ferrous sulphate, aluminium chloride and alum enhanced the peak viscosity at lower concentrations and with increase in concentration of the salts, the viscosity values showed a gradual decrease. When the concentration of ferrous sulphate increased from 0.05 to $0.5 \%$, the viscosity was enhanced from 2.53 to $2.78 \mathrm{~Pa}$ s and then showed a fall to 2.68 and $2.12 \mathrm{~Pa} s$ at 1 and $5 \%$ concentrations, respectively. After an initial enhancement in viscosity at $0.05 \%$ to $2.51 \mathrm{~Pa} \mathrm{~s}$, alum brought about a gradual reduction with salt concentration to reach $1.72 \mathrm{~Pa}$ $\mathrm{s}$ at $5 \%$ concentration. The granule structure was weakened somewhat by the addition of salts which resulted in increased peak viscosity. But at higher concentrations of these acidic salts, the effect of $\mathrm{pH}$ predominated and caused a fall in viscosity. This is in accordance with the results obtained earlier with the Brabender Viscograph [4, 5]. These salts effected a breakdown of starch due to their acidic nature and this property is related to the concentration of the salts. Sajeev et al. reported a similar pattern of viscosity change for cassava starch prepared by the addition of alum ( $50 \mathrm{mM})$ during the extraction process of the starch [16].

An increase in peak viscosity was observed with acetic and hydrochloric acids at 0.05 and $0.1 \%$; however, at $0.5 \%$ and higher concentrations, a fall in viscosity was noticed. The drop in viscosity at higher concentration of acetic acid was not as high as that obtained with hydrochloric acid. The higher acidity of hydrochloric acid could be responsible for the lowering of viscosity. A similar drop in viscosity parameters was observed while studying the 
effect of acids on settling properties of cassava starch [17]. Wurzburg observed that the reduction in viscosity by acids was due to their hydrolysing action and suggested that formation of radial fissures on starch granules when heated in water could be the reason for the drop in viscosity [18].

The addition of sodium metabisulphite to cassava starch increased the peak viscosity to $2.34 \mathrm{~Pa} \mathrm{~s}$ at $0.05 \%$ and $2.41 \mathrm{~Pa} s$ at $0.1 \%$, respectively, thereafter the peak viscosity remained constant. A similar observation was made by John et al. while studying the effect of potassium metabisulphite during extraction of starch from Xanthosoma tubers [19]. The reduction in viscosity at concentrations above $3.12 \mathrm{mM}$ was attributed to the decrease in the $\mathrm{pH}$ due to the sulphur dioxide released [20].

Sodium hypochlorite brought about a gradual decrease in peak viscosity from $1.98 \mathrm{~Pa}$ s at $0.05 \%$ to $1.84 \mathrm{~Pa}$ s at $0.5 \%$. The viscosity then sharply dropped to $0.76 \mathrm{~Pa}$ s at a concentration of $1.0 \%$. This could be attributed to the oxidative effect of hypochlorite. A decrease in peak viscosity of cassava starch at low concentrations of hypochlorite $(0.17 \mathrm{mM})$ was reported $[18,20]$. John et al. also reported that the degradation of starch granules by oxidation with sodium hypochlorite is responsible for the lowering of viscosity [19].

\subsection{Effect on breakdown in viscosity}

When a starch suspension is subjected to conditions of heat and shear, the granules swell and attain high viscosity. But the swollen granules rupture on continuous heating, resulting in a fall in viscosity. For the control starch, the viscosity breakdown was $1.1 \mathrm{~Pa}$ s. Salts of monovalent cations such as sodium chloride, sodium sulphite and sodium thiosulphate brought about a reduction in breakdown with increased concentration of salts (Fig. 2). With calcium chloride, there was a slight increase in breakdown of viscosity at a concentration of $0.05 \%$, but there was a decrease at 0.1 and $0.5 \%$ levels. At $1 \%$ concentration again an increase was noted followed by a decrease at 2.5 and $5 \%$ levels. The acidic salts showed a similar pattern for viscosity breakdown with increase in concentration. With $\mathrm{FeSO}_{4}$, the breakdown increased with concentration up to $1 \%$, thereafter it gradually decreased. Alum and aluminium chloride brought about an increase in viscosity breakdown up to $0.05 \%$ concentration and then a gradual decrease was observed. At this concentration, the reduced breakdown could be traced to the corresponding low peak viscosity. The higher breakdown in the case of alum and aluminium chloride brings about disruption of starch granules [10]. Thus, sodium chloride, sodium sulphite and sodium
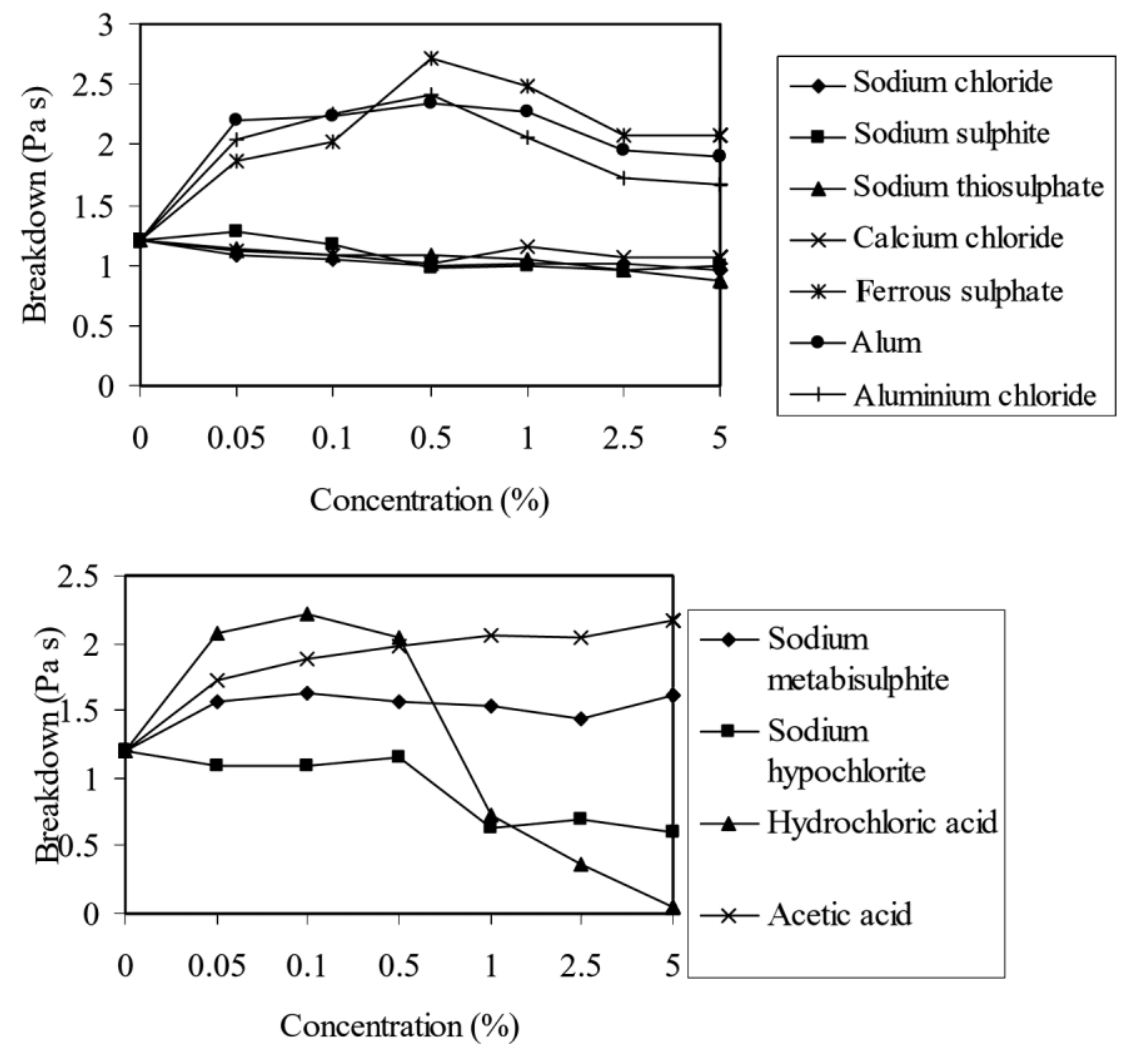

Fig. 2. Effect of different salts, oxidising agents and acids on the breakdown in viscosity of cassava starch. 
thiosulphate stabilised the starch pastes, while ferrous sulphate, aluminium chloride and alum caused a decrease in paste stability.

The paste stability of cassava flour was also reported to be improved by sodium chloride and sodium sulphate with the latter showing better stability [6]. An increased breakdown at higher levels of aluminium chloride in Brabender studies with cassava starch is reported [5]. The lowering of $\mathrm{pH}$ at higher aluminium chloride concentrations evidently causes the breakdown.

Hydrochloric acid initially increased the viscosity breakdown at $0.5 \%$, higher concentrations resulted in a rapid decrease; while acetic acid caused a steady increase throughout (Fig. 2). The observed lowering of breakdown at higher concentrations of hydrochloric acid $(0.72 \mathrm{~Pa}$ s and $1 \%$ and $0.04 \mathrm{~Pa}$ a a $5 \%$ ) could be due to the corresponding lowering of peak viscosities at these concentrations.

Sodium hypochlorite brought about a fall in breakdown with increase in concentration. Being an oxidising agent sodium hypochlorite caused a lowering of peak viscosity, which is also reflected in breakdown. However, sodium metabisulphite significantly enhanced the breakdown, although there was no significant change with increase in concentration. This can be correlated to the observed peak viscosity values.

The final hot viscosity (peak-breakdown) showed the largest decrease if the valency of both cation and anion is largest. The decrease in final viscosity on the addition of hydrolysing and oxidising agents becomes more prominent with the concentration and efficacy of the reagents.

A higher peak viscosity indicates a higher swelling power of the starch granules. The granule structure is weakened by those salts that increase peak viscosity. These slightly weakened granules are more affected by prolonged stirring at high temperature, and this leads to the large breakdown value of the starches. A salt that gives a high peak viscosity actually promotes the weakening of the starch granules, resulting in lower final viscosity. This also explains the high swelling volumes noticed for low concentrations of $\mathrm{FeSO}_{4}, \mathrm{AlCl}_{3}$ and alum.

\subsection{Effect on pasting temperature}

All the salts enhanced the pasting temperature of cassava starch with increase in concentration (Tab. 1). The ability of the salts to modify the gelatinisation temperature of starch has been attributed to their influence on the structure of water. Strongly hydrated ions increase the structural order of water with consequent decrease in the ability to gelatinise starch. Conversely, weakly hydrated ions distruct the structure of water and assist gelatinisation. The chloride ion is located rather in the centre in the lyotropic series and thus has little effect on the water structure [21]. An increase in pasting temperature was observed with sodium thiosulphate and sodium sulphite also $[5,22]$. There was almost no significant change in pasting temperature of cassava starch in the presence of acetic acid, however, an increase was observed with hydrochloric acid.

\subsection{DSC characteristics}

The thermal behaviour of the starch in presence of aluminium chloride, sodium sulphite and sodium thiosulphate was determined (Tabs. 2-3). The addition of sodium sulphite to starch during gelatinisation resulted in a slight increase in $T_{\text {onset }}$ and $T_{\text {end }}$ values and with increase in

Tab. 1. Pasting temperature $\left({ }^{\circ} \mathrm{C}\right)$ of cassava starch in presence of salts, acids and oxidising agents.

\begin{tabular}{|c|c|c|c|c|c|c|c|}
\hline Salt/concentration [\%] & 0.00 & 0.05 & 0.10 & 0.50 & 1.0 & 2.5 & 5.0 \\
\hline Sodium chloride & $69.5(0.15)$ & $71.2(0.25)$ & $71.92(0.20)$ & $73.2(0.19)$ & $74.3(0.14)$ & $76.7(0.15)$ & $77.5(0.15)$ \\
\hline Sodium sulphite & & $70.7(0.15)$ & $71.5(0.12)$ & $73.5(0.10)$ & $73.9(0.20)$ & $76.7(0.1$ & $77.2(0.12)$ \\
\hline Sodium thiosulphate & & $69.9(0.12)$ & $71.0(0.10)$ & $71.9(0.12)$ & $73.0(0.16)$ & $75.2(0.05)$ & $77.2(0.10)$ \\
\hline Calcium chloride & & $70.7(0.10)$ & $71.1(0.13)$ & $72.8(0.02)$ & $73.5(0.05)$ & $76.0(0.00)$ & $76.7(0.04)$ \\
\hline Ferrous sulphate & & $69.9(0.05)$ & $70.3(0.10)$ & $70.3(0.07)$ & $71.0(0.02)$ & $72.6(0.10)$ & $73.5(0.05)$ \\
\hline Aluminium chloride & & $70.7(0.04)$ & $70.7(0.00)$ & $71.9(0.10)$ & $72.3(0.01)$ & $75.2(0.02)$ & $75.9(0.00)$ \\
\hline Alum & & $69.9(0.10)$ & $69.4(0.03)$ & $71.5(0.03)$ & $71.1(0.03)$ & $73.5(0.00)$ & $73.5(0.01)$ \\
\hline Sodium metabisulphite & & $70.3(0.05)$ & $70.7(0.10)$ & $72.3(0.10)$ & $73.1(0.08)$ & $75.0(0.03)$ & $74.8(0.03)$ \\
\hline Sodium hypochlorite & & $70.3(0.15)$ & $70.3(0.13)$ & $69.5(0.06)$ & $74.4(0.05)$ & $74.3(0.10)$ & $74.3(0.05)$ \\
\hline Hydrochloric acid & & $69.6(0.05)$ & $70.5(0.05)$ & $70.7(0.08)$ & $73.5(0.05)$ & $75.1(0.01)$ & $74.6(0.01)$ \\
\hline Acetic acid & & $69.9(0.10)$ & $70.0(0.05)$ & $69.5(0.03)$ & $69.1(0.02)$ & $69.4(0.05)$ & $68.8(0.01)$ \\
\hline
\end{tabular}

Values in parenthesis are the standard deviations of three replicates. 
Tab. 2. Thermal properties (DSC) of cassava starch in presence of aluminium chloride, sodium sulphite and sodium thiosulphate.

\begin{tabular}{lllllll}
\hline $\begin{array}{l}\text { Salt/concentration } \\
{[\%]}\end{array}$ & \multicolumn{2}{l}{ Aluminium chloride } & \multicolumn{2}{l}{ Sodium sulphite } & \multicolumn{2}{l}{ Sodium thiosulphate } \\
\cline { 2 - 7 } & $T_{\text {onset }}\left[{ }^{\circ} \mathrm{C}\right]$ & $T_{\text {end }}\left[{ }^{\circ} \mathrm{C}\right]$ & $T_{\text {onset }}\left[{ }^{\circ} \mathrm{C}\right]$ & $T_{\text {end }}\left[{ }^{\circ} \mathrm{C}\right]$ & $T_{\text {onset }}\left[{ }^{\circ} \mathrm{C}\right]$ & $T_{\text {end }}\left[{ }^{\circ} \mathrm{C}\right]$ \\
\hline Control & $63.9(0.30)$ & $76.0(0.10)$ & & & & \\
\hline 0.001 & $64.6(0.25)$ & $77.2(0.20)$ & $64.4(0.10)$ & $76.6(0.10)$ & $63.8(0.20)$ & $76.1(0.00)$ \\
0.003 & $64.7(0.10)$ & $77.4(0.15)$ & $63.7(0.20)$ & $75.7(0.15)$ & $64.4(0.10)$ & $75.6(0.10)$ \\
0.005 & $64.6(0.00)$ & $77.1(0.05)$ & $63.9(0.15)$ & $76.5(0.10)$ & $64.7(0.10)$ & $76.8(0.00)$ \\
0.010 & $64.3(0.00)$ & $75.8(0.00)$ & $64.6(0.20)$ & $77.0(0.20)$ & $64.4(0.20)$ & $76.2(0.20)$ \\
0.025 & $64.5(0.10)$ & $76.4(0.10)$ & $64.5(0.15)$ & $76.5(0.10)$ & $64.7(0.10)$ & $76.5(0.10)$ \\
0.050 & $64.6(0.15)$ & $76.1(0.05)$ & $64.3(0.10)$ & $76.8(0.00)$ & $64.2(0.00)$ & $76.3(0.10)$ \\
0.100 & $65.2(0.10)$ & $76.8(0.10)$ & $66.2(0.15)$ & $77.8(0.10)$ & $64.7(0.00)$ & $77.3(0.00)$ \\
0.250 & $66.4(0.50)$ & $77.7(0.35)$ & $66.3(0.10)$ & $78.3(0.00)$ & $64.8(0.10)$ & $76.8(0.10)$ \\
0.500 & $67.2(0.15)$ & $78.4(0.10)$ & $66.8(0.10)$ & $78.6(0.10)$ & $65.9(0.10)$ & $77.8(0.10)$ \\
1.000 & $69.0(0.10)$ & $80.3(0.15)$ & $68.3(0.10)$ & $79.9(0.15)$ & $65.8(0.00)$ & $76.9(0.00)$ \\
\hline
\end{tabular}

Values in parenthesis are the standard deviations of three replicates.

Tab. 3. Enthalpy of gelatinisation $(\Delta H, \mathrm{~J} / \mathrm{g})$ of cassava starch in presence of aluminium chloride, sodium sulphite and sodium thiosulphate.

\begin{tabular}{llll}
\hline $\begin{array}{l}\text { Salt/concen- } \\
\text { tration [\%] }\end{array}$ & $\begin{array}{l}\text { Aluminium } \\
\text { chloride }\end{array}$ & $\begin{array}{l}\text { Sodium } \\
\text { sulphite }\end{array}$ & $\begin{array}{l}\text { Sodium } \\
\text { thiosulphate }\end{array}$ \\
\hline Control & $14.1(0.05)$ & & \\
\hline 0.001 & $13.8(0.35)$ & $13.7(0.06)$ & $13.1(1.12)$ \\
0.003 & $14.1(0.05)$ & $13.9(0.08)$ & $13.7(0.23)$ \\
0.005 & $14.1(0.08)$ & $14.1(0.06)$ & $13.9(0.11)$ \\
0.010 & $13.7(0.05)$ & $14.1(0.12)$ & $14.0(0.55)$ \\
0.025 & $13.5(0.06)$ & $14.6(0.5)$ & $13.3(0.62)$ \\
0.050 & $13.8(0.22)$ & $14.6(0.01)$ & $14.1(0.27)$ \\
0.100 & $13.3(0.10)$ & $14.1(0.05)$ & $14.2(0.15)$ \\
0.250 & $13.07(0.36)$ & $14.3(0.04)$ & $15.0(0.58)$ \\
0.500 & $13.7(0.06)$ & $14.5(0.09)$ & $14.2(0.21)$ \\
1.000 & $14.6(0.04)$ & $14.3(0.01)$ & $15.2(0.08)$ \\
\hline
\end{tabular}

Values in parenthesis are the standard deviations of three replicates.

concentration of the salt, the $T_{\text {onset }}$ values gradually increased (Tab. 2). With sodium sulphite, there was no significant change in the gelatinisation temperatures up to $0.05 \%$ concentration, but above that an increase was noticed. In the case of sodium thiosulphate, there was a slight increase of about $2^{\circ} \mathrm{C}$ in the $T_{\text {onset }}$ values on addition of $1 \%$ of the salt. The $\Delta H$ values were slightly lowered when starch was treated with aluminium chloride at concentrations above $0.01 \%$. With sodium thiosulphate and sodium sulphite, an increase was observed in the enthalpy of gelatinisation (Tab. 3). The delayed gelatinisation in presence of aluminium chloride, sodium sulphite, and sodium thiosulphate observed by the DSC confirms the results of the pasting characteristics of the starches observed from viscosity studies.

Chinachoti et al. reported that the $T_{\mathrm{o}}$ and $T_{\mathrm{p}}$ of wheat starch increased as the salt concentrations increased [11]. Eliasson and Gudmundsson have reviewed the effect of salts on various starches and found that it depends on the type of salt as well as on the concentration [23]. With $\mathrm{NaCl}$ it has been observed that the gelatinisation temperature first increased with salt concentration, and then decreased. The enthalpy also showed a similar behaviour. The authors reported a decrease in gelatinisation parameters for potato and canna starches, whereas for maize and rice starches first an increase and then a decrease were observed with increasing $\mathrm{NaCl}$ concentration. The increase in gelatinisation temperature and variations in $\Delta H$ of maize starch in presence of various salts was also reported [24]. The rise of the gelatinisation temperature could be explained on the basis of two factors, viz., water structure and electrostatic interaction between starch and ions. Anions of high charge density were found to increase the structure of water and stabilise the starch granules; anions of low charge density not only break the water structure but also tend to form helical complexes with starch molecules, destabilising the granules. Because starch is basically electronegative in nature, anions tend to repel the $\mathrm{OH}$ groups of starch and stabilise starch granules and the repulsion is proportional to the charge density. Cations, on the other hand, attract $\mathrm{OH}$ groups and tend to destabilise the starch granules. However, both effects stabilise starch granules and as the charge density and concentration of anions increase, the gelatinisation temperature increases. For cations, the 
increased charge density results in more highly structured water, which stabilises the starch granules. Thus the effect of salts on the gelatinisation properties of starch is found to depend on the type of salt and concentration.

\subsection{Swelling volume}

At lower concentrations $(<1 \%$ ) of sodium chloride, a slight decrease in the swelling volume of cassava starch occurred, but at 2.5 and $5 \%$ levels, an increase was noticed. Revamma reported a similar effect on the swelling volume of cassava starch in presence of sodium chloride at different temperature and pressure conditions [5]. At concentrations below $1 \%$, sodium sulphite did not bring about any significant change in swelling volume, however, at higher concentrations, an increase was observed. Sodium thiosulphate, calcium chloride and ferrous sulphate decreased the swelling volume with increasing salt concentration (Tab. 4). With $0.05 \%$ alum and 0.05 and $0.1 \%$ aluminium chloride, an increased swelling of starch was observed, but a gradual decrease was noted at higher concentrations. At higher concentrations of $\mathrm{FeSO}_{4}$, aluminium chloride and alum, a very pronounced decrease in swelling volume was observed. This could be due to the low $\mathrm{pH}$ of the suspensions, which induce starch hydrolysis. This is confirmed by the very low final hot viscosities of starch observed in these solutions. A steady decline in swelling volume has been observed when alum was used to aid settling cassava starch; the effect was much less pronounced compared to the use of acid [16].

With sodium hypochlorite, at concentrations above $0.1 \%$, a sharp decrease in swelling volume was found, whereas sodium metabisulphite increased the swelling volume.
Hydrochloric acid sharply reduced the swelling volume with increasing concentration; however, acetic acid showed an increase in swelling volume with concentration up to $1 \%$ and above that there was a sharp decline to 5.5 and $3 \mathrm{~mL} / \mathrm{g}$ at 2.5 and $5 \%$ concentrations, respectively. The low $\mathrm{pH}$ and the resulting starch hydrolysis could be responsible for the very low swelling volumes at higher concentrations of the acids.

\subsection{Paste clarity}

The clarity of the starch paste was found to decrease with increase in concentration of sodium chloride, sodium thiosulphate and calcium chloride (Tab. 5). With sodium sulphite at concentrations of 0.05 and $0.1 \%$, an increase in \% light transmittance was noticed followed by a gradual decrease at higher concentrations. Addition of aluminium chloride increased the paste clarity. With $0.05 \%$ alum, there was a decrease in paste clarity, but at concentrations above this, increase in $\% T$ was observed up to $1 \%$ and again decrease at higher concentrations. The presence of sodium hypochlorite and hydrochloric acid enhanced the starch paste clarity, while sodium metabisulphite, after a small increase at $0.05 \%$ concentration, brought about a decrease in $\% T$ of the pastes up to $1 \%$ and again there was an increase at 2.5 and $5 \%$ levels. Acetic acid at 0.05 and $0.1 \%$ levels, reduced the light transmittance of the starch paste, but from $0.5 \%$ onwards, more clear pastes were obtained. An increase in paste clarity was reported with cassava starch settled in presence of hydrochloric acid [16]. The H-bonding present in the starch granules reflect the light and thereby decrease the paste clarity. Therefore, breaking of $\mathrm{H}$-bonds gives more clear pastes. With acids the hydrolysing effect

Tab. 4. Swelling volumes of cassava starch in presence of salts, acids and oxidising agents.

\begin{tabular}{lllllrrr}
\hline Salts/concentration [\%] & Control & \multicolumn{1}{l}{0.05} & \multicolumn{1}{l}{0.10} & \multicolumn{1}{l}{0.50} & \multicolumn{1}{l}{1.0} & \multicolumn{1}{l}{2.5} & \multicolumn{1}{l}{5.0} \\
\hline Sodium chloride & $31.0(0.05)$ & $25.5(0.04)$ & $25.5(0.50)$ & $26.5(0.20)$ & $28.5(0.35)$ & $29.0(0.01)$ & $32.5(0.05)$ \\
Sodium sulphite & $30.5(0.20)$ & $29.0(0.06)$ & $29.5(0.05)$ & $29.0(0.04)$ & $31.0(0.25)$ & $36.0(0.03)$ & $36.0(0.01)$ \\
Sodium thiosulphate & $30.5(0.25)$ & $28.0(0.02)$ & $28.0(0.02)$ & $26.0(0.04)$ & $26.5(0.05)$ & $25.5(0.03)$ & $24.0(.020)$ \\
Calcium chloride & $30.5(0.15)$ & $28.5(0.01)$ & $27.0(0.04)$ & $27.5(0.15)$ & $28.0(0.05)$ & $26.5(0.05)$ & $27.5(0.00)$ \\
Ferrous sulphate & $31.0(0.25)$ & $30.0(0.25)$ & $34.0(0.05)$ & $25.0(0.02)$ & $19.0(0.05)$ & $17.0(0.20)$ & $11.5(0.05)$ \\
Aluminium chloride & $31.0(0.05)$ & $39.5(0.10)$ & $43.5(0.01)$ & $31.5(0.01)$ & $23.0(0.12)$ & $4.5(0.02)$ & $2.0(0.10)$ \\
Alum & $31.0(0.20)$ & $38.5(0.05)$ & $25.0(0.05)$ & $17.5(0.01)$ & $11.0(0.15)$ & $5.5(0.02)$ & $1.0(0.02)$ \\
Sodium metabisulphite & $31.0(0.5)$ & $39.5(0.05)$ & $42.0(0.10)$ & $41.0(0.02)$ & $37.0(0.10)$ & $40.0(0.01)$ & $41.0(0.02)$ \\
Sodium hypochlorite & $31.0(0.4)$ & $30.0(0.50)$ & $8.5(0.02)$ & $3.0(0.02)$ & $1.5(0.10)$ & $1.0(0.10)$ & $1.0(0.20)$ \\
Hydrochloric acid & $31.0(0.5)$ & $28.0(0.10)$ & $2.5(0.05)$ & $2.0(0.03)$ & $1.0(0.10)$ & $1.0(0.01)$ & $1.0(0.05)$ \\
Acetic acid & $30.5(0.5)$ & $51.5(0.03)$ & $50.0(0.04)$ & $49.5(0.15)$ & $49.0(0.20)$ & $5.5(0.05)$ & $3.0(0.25)$ \\
\hline
\end{tabular}

Values in parenthesis are the standard deviations of three replicates. 
Tab. 5. Percentage light transmittance ( $\% T)$ of cassava starch paste in presence of salts, acids and oxidising agents.

\begin{tabular}{|c|c|c|c|c|c|c|c|}
\hline Salts/concentration [\%] & Control & 0.05 & 0.10 & 0.50 & 1.0 & 2.5 & 5.0 \\
\hline Sodium chloride & $24.09(2.01)$ & $15.52(1.88)$ & $13.21(1.05)$ & $12.22(1.88)$ & $10.33(1.95)$ & $7.76(2.01)$ & $6.29(1.98)$ \\
\hline Sodium sulphite & & $39.26(2.01)$ & $28.38(1.88)$ & $22.13(1.98)$ & $17.86(1.98)$ & $17.86(2.01)$ & $17.58(1.86)$ \\
\hline Sodium thiosulphate & & $21.73(1.58)$ & $21.28(1.64)$ & $20.94(1.56)$ & $17.78(1.88)$ & $17.30(1.05)$ & 17.02 \\
\hline Calcium chloride & & $21.83(1.98)$ & 21.04 & & $17.33(1.75)$ & $13.77(1.88)$ & $2(1.95)$ \\
\hline Ferrous sulphate & & & & & 1.05) & 63. & 63. \\
\hline Alumin & & & & & & 70. & $2.01)$ \\
\hline Alum & & $21.93(1.88)$ & $32.66(1.98)$ & $32.58(1.05)$ & $32.43(1.88)$ & $30.97(1.75)$ & $(2.05)$ \\
\hline Sodium metabisulphite & & $24.89(1.78)$ & $24.21(2.31)$ & $11.72(1.95)$ & $10.74(1.66)$ & $12.53(1.05)$ & $17.34(2.01)$ \\
\hline Sodium hypochlorite & & $19.45(1.98)$ & $61.80(2.01)$ & $86.30(2.01)$ & $87.10(1.98)$ & $95.72(1.95)$ & $95.50(2.01)$ \\
\hline Hydrochloric acid & & $57.41(1.05)$ & $79.80(1.05)$ & $87.90(1.55)$ & $89.13(1.05)$ & $88.72(1.98)$ & $89.33(1.05)$ \\
\hline Acetic acid & & $17.14(1.05)$ & $16.79(2.01)$ & $25.29(2.01)$ & $34.75(1.98)$ & $58.75(1.05)$ & $68.39(1.75)$ \\
\hline
\end{tabular}

Values in parenthesis are the standard deviations of three replicates.

could lead to breakage of $\mathrm{H}$-bonds and thereby increase in paste clarity. The increase in paste clarity with the acidic salts and acids is in agreement with the behaviour of swelling volume and final hot viscosity. The increase in $\% T$ is due to the disruption of starch granules by hydrolytic or oxidative (in case of sodium hypochlorite) processes.

\section{Conclusion}

The effect of different salts, acids and oxidising agents on the pasting and gelatinisation properties of cassava starch was studied. Low concentrations of acidic salts, such as ferrous sulphate, alum and aluminium chloride and acids enhanced the peak viscosity, swelling volume, pasting temperature and paste clarity of cassava starch. The nature and concentration of the salts affected the paste and thermal properties of cassava starch. The presence of various components influenced the starch properties differently and this study is of interest because starch is usually used along with other ingredients such as salts, acids, surfactants, lipids, etc. Such investigations are of importance in the food industry also because of the frequent presence of electrolytes in food systems.

\section{Acknowledgements}

The authors wish to acknowledge Dr. S. Edison, Director, and Dr. G. Padmaja, Head, Division of Crop Utilization for the facilities provided and Mr. J. Sreekumar, Scientist (SS), Central Tuber Crops Research Institute, Thiruvananthapuram, India for the statistical analysis of the data.

\section{References}

[1] S. N. Moorthy: Effect of different types of surfactants on cassava starch properties. J. Agric. Food Chem. 1985, 35, 1227-1232.

[2] R. R. Roach, R. C. Hoseney: Effect of certain surfactants on the swelling, solubility and amylograph consistency of starch. Cereal Chem. 1995, 72, 571-577.

[3] N. Krog: Influence of food emulsifiers on pasting temperature and viscosity of various starches. Stärke 1973, 25, 22 27.

[4] D. B. Mat Hashim, S. N. Moorthy, J. R. Mitchell, S. E. Hill, K. J. Linfoot, J. M. V. Blanshard: The effect of low levels of antioxidants on the swelling and solubility of cassava starch. Starch/Stärke 1992, 44, 471-475.

[5] R. Revamma: Effect of different types of salts and sugars on the rheological properties of cassava starch. PhD thesis, Department of Chemistry, University of Kerala, Thiruvananthapuram, Kerala, India, 2000.

[6] K. C. M. Raja, S. V. Ramakrishna: Influence of salts on pasting temperature characteristics of cassava. Food Chem. 1988, 28, 311-317.

[7] A. C. Eliasson: A calorimetric investigation of the influence of sucrose on the gelatinisation of starch. Carbohydr. Polym. 1992, 18, 131-138.

[8] G. B. Crosbie: The relationship between starch swelling properties, paste viscosity and boiled noodle quality in wheat flours. J. Cereal Sci. 1991, 13, 145-150.

[9] L. A. Bello-Perez, O. Paredes-Lopez: Starch and amylopectin- Effects of solutes on clarity of pastes. Starch/Stärke 1996, 48, 205-207.

[10] C. Bircan, S. A. Barringer: Salt-Starch interactions as evidenced by viscosity and dielectric property measurements. J. Food Sci. 1998, 63, 983-986.

[11] P. Chinachoti, M. Kim-Shim, F. Mari, L. Lo: Gelatinisation of wheat starch in presence of sucrose and sodium chloride: correlation between gelatinisation temperature and water mobility as determined by oxygen-17 Nuclear magnetic resonance. Cereal Chem. 1991, 68, 245-248.

[12] S. E. Hill, D. A. Gray: Effect of sulphite and propylgallate or ferulic acid on the thermal depolymerisation of food polysaccharides. J. Sci. Food Agric. 1999, 79, 471-475. 
[13] B. L. Wedzicha: Chemistry of Sulphur Dioxide in Foods, Elsevier, London-New York, 1984, 384.

[14] S. L. Wellington: Biopolymer solution viscosity stabilizationpolymer degradation and antioxidant: Use. Soc. Pet. Eng. J. 1983, 9296, 901-912.

[15] C. O. Moore, J. V. Tuschhof, C. W. Hastings, R. V. Schanefelt: Applications of starches in Foods, in Starch Chemistry and Technology, Vol. II. (Ed. R. L. Whistler, J. N. BeMiller, E. F. Paschall) Academic Press, New York, 1984, 575-590.

[16] M. S. Sajeev, S. N. Moorthy: Swelling and viscometric characteristics of cassava starch settled in the presence of different chemicals, in Trends in Carbohydrate Chemistry, Vol. 7 (Ed. P. L. Soni) Surya International Publications, Dehradun, India, 2001, 117-125.

[17] M. S. Sajeev, R. Kailappan, V. V. Sreenarayanan, K. Thangavel: Kinetics of gravity settling of cassava starch in its aqueous suspension. Biosystems Eng. 2001, 83, 327-337.

[18] O. B. Wurzburg: Converted starches, in Modified Starches: Properties and Uses (Ed. O. B. Wurzburg), CRC Press, Boca Raton, FL, 1989, 17-41.

[19] J. K. John, V. Sunitha Rani, K. C. M. Raja, S. N. Moorthy: Physicochemical and enzyme susceptibility characteristics of starch extracted from chemically pretreated Xanthosoma saggittifolium roots. Starch/Stärke 1999, 51, 86-89.

[20] M. S. Sajeev, S. N. Moorthy, R. Kailappan, V. Sunitha Rani: Gelatinisation characteristics of cassava starch settled in the presence of different chemicals. Starch/Stärke 2003, 55, 247-257.

[21] B. M. Gough, J. N. Pybus: Effect of metal cations on the swelling and gelatinisation behaviour of large wheat starch granules. Stärke 1973, 25, 123-130.

[22] B. J. Oosten: Tentative hypothesis to explain how electrolytes affect the gelatinization temperature of starches in water. Starch/Stärke 1982, 34, 233-239.

[23] A. C. Eliasson, M. Gudmundsson: Starch: Physiochemical and functional properties, in Carbohydrates in Food (Ed. A. C. Eliasson), Marcel Decker Inc. New York, 1996, 431-503.

[24] J.-L. Jane: Mechanism of starch gelatinisation in neutral salt solutions. Starch/Stärke 1993, 45, 161-166.

(Received: March 24, 2005)

(Revised: July 3, 2005)

(Accepted: July 13, 2005) 